Supporting Information

for

\title{
Acid Leaching of desilication products: implications for acid neutralisation of bauxite residue
}

Hong Peng*, Tae Kim, James Vaughan

School of Chemical Engineering, The University of Queensland, Brisbane, Australia

(*corresponding author: h.peng2@uq.edu.au) 


\section{Figure and Table Lists}

Figure S1. Main elements ( $\mathrm{Na}, \mathrm{Al}$ and $\mathrm{Si}$ ) concentration in solution during acid dissolution of three solid samples (Zeolite LTA, sodalite and Bauxite residue) at three different concentrations during testing time.

Figure S2. X-ray photoelectron spectroscopy with wide-scan range of binding energy from 0 to $1200 \mathrm{eV}$ and sub-band under $200 \mathrm{eV}$ of Zeolite LTA solid treated by $0 \mathrm{M}$, $0.01 \mathrm{M}$ and $0.1 \mathrm{M} \mathrm{HCl}$ acid.

Figure S3. X-ray photoelectron spectroscopy with wide-scan range of binding energy from 0 to $1200 \mathrm{eV}$ sub-band under $200 \mathrm{eV}$ of Sodalite solid treated by $0 \mathrm{M}, 0.01 \mathrm{M}$ and $0.1 \mathrm{M} \mathrm{HCl}$ acid.

Figure S4. ${ }^{1} \mathrm{H},{ }^{23} \mathrm{Na},{ }^{27} \mathrm{Al}$ and ${ }^{29} \mathrm{Si}$ NMR spectra of Zeolite LTA phase treated by $0 \mathrm{M}$, $0.01 \mathrm{M}$ and $0.1 \mathrm{M}$ acid.

Figure S5. ${ }^{1} \mathrm{H},{ }^{23} \mathrm{Na},{ }^{27} \mathrm{Al}$ and ${ }^{29} \mathrm{Si} \mathrm{NMR}$ spectra of sodalite phase treated by $0 \mathrm{M}, 0.01 \mathrm{M}$ and $0.1 \mathrm{M}$ acid.

Figure S6. Speciation diagram for the aluminate-water system at $25^{\circ} \mathrm{C}$ as a function of $\mathrm{pH}$ values from 1 to 14 .

Table S1 The standard Gibbs energies of formation of species relevant with aluminum ions in $\mathrm{pH}$ value range from 2 to 14 

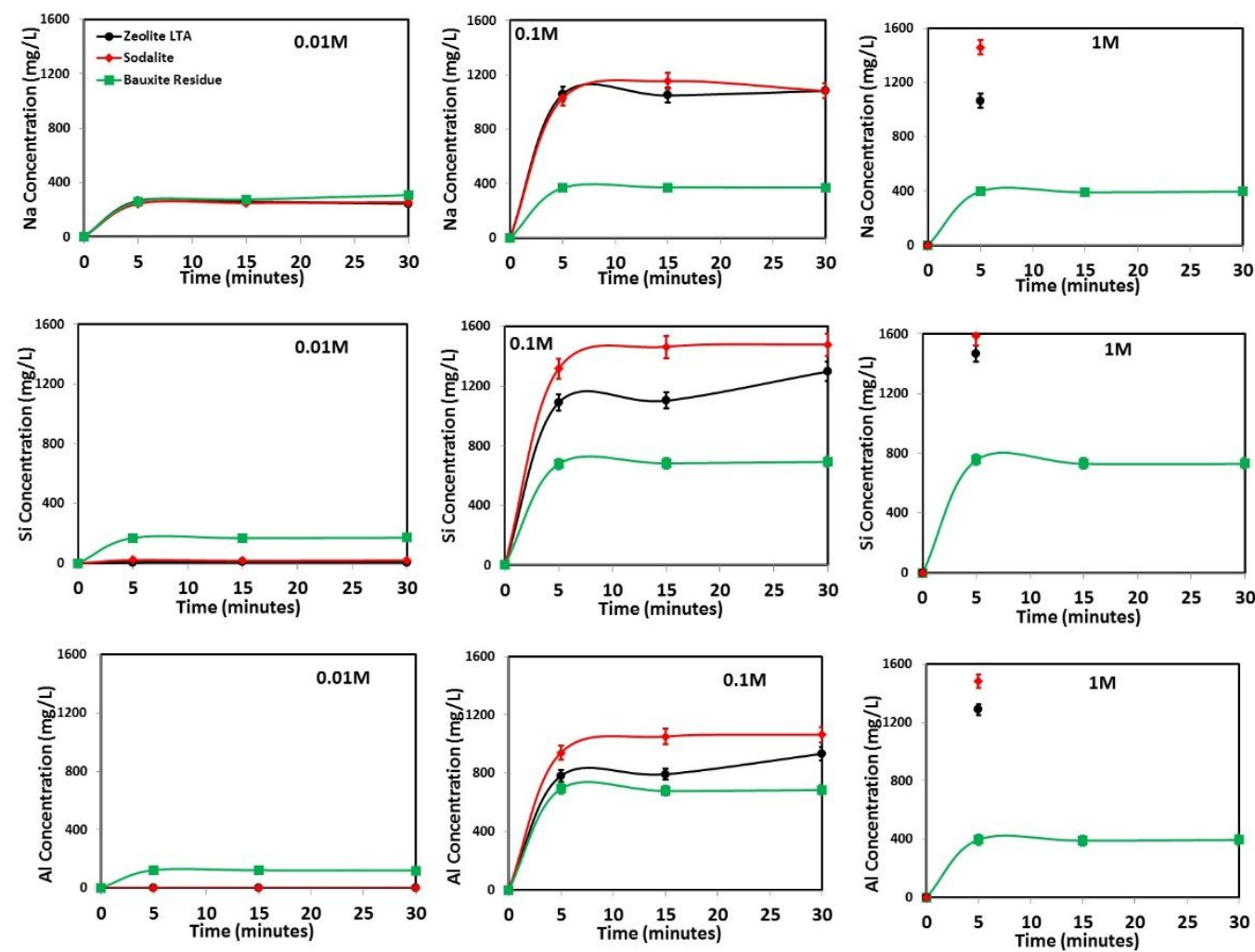

Figure S1. Main elements ( $\mathrm{Na}, \mathrm{Al}$ and $\mathrm{Si})$ concentration in solution during acid dissolution of three solid samples (Zeolite LTA, sodalite and Bauxite residue) at three different concentrations during testing time. 

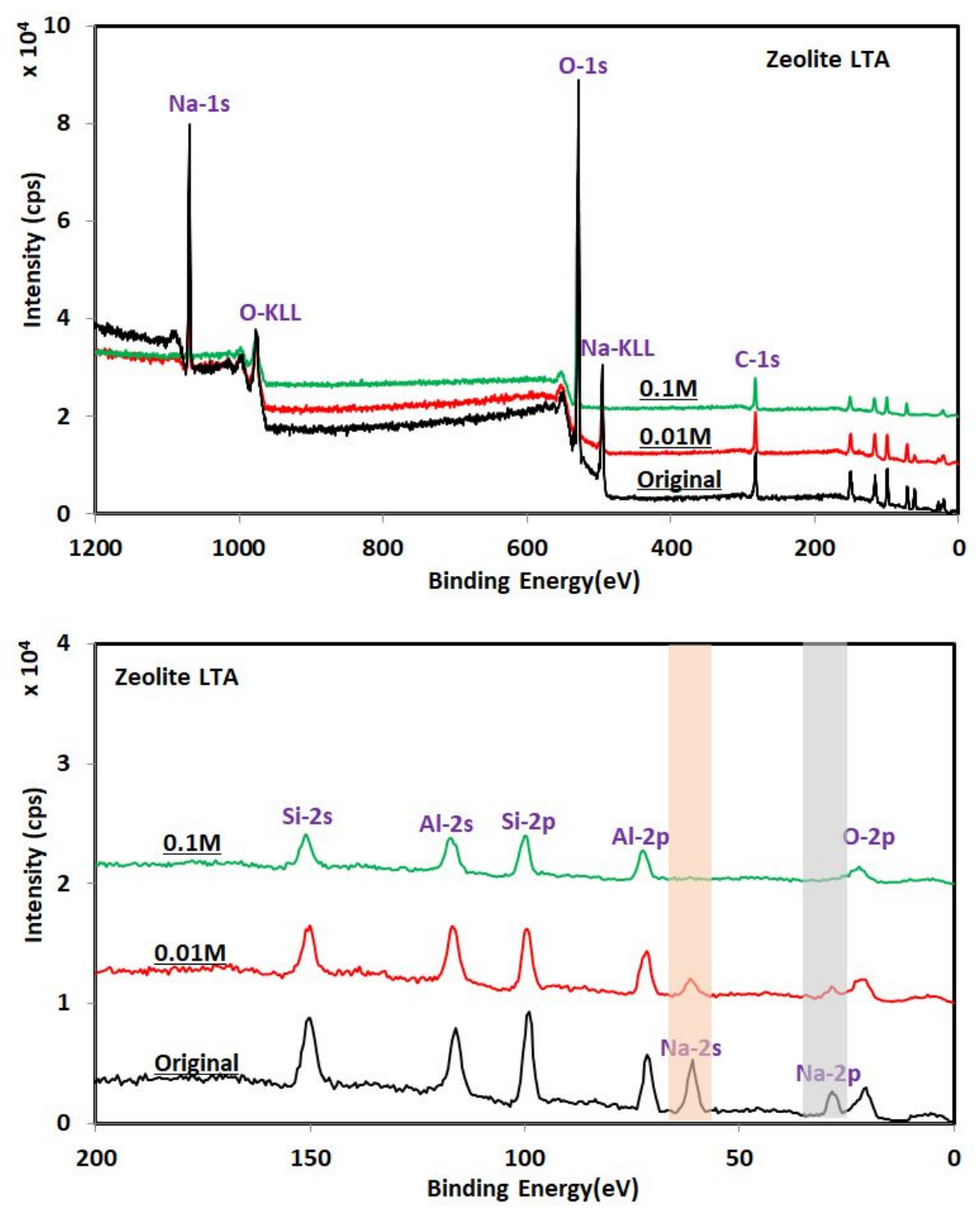

Figure S2. X-ray photoelectron spectroscopy with wide-scan range of binding energy from 0 to $1200 \mathrm{eV}$ and sub-band under $200 \mathrm{eV}$ of Zeolite LTA solid treated by $0 \mathrm{M}$, $0.01 \mathrm{M}$ and $0.1 \mathrm{M} \mathrm{HCl}$ acid. 

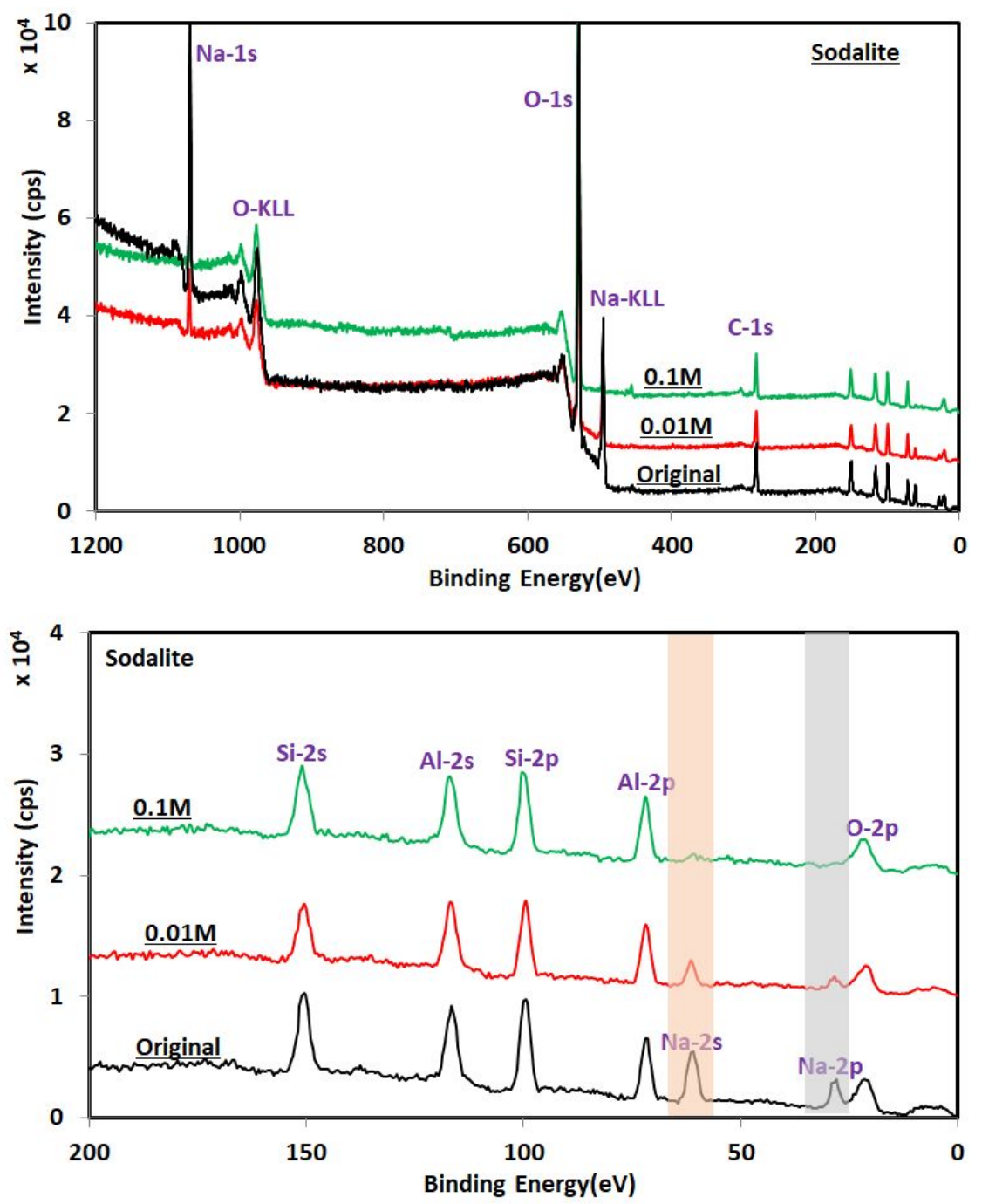

Figure S3. X-ray photoelectron spectroscopy with wide-scan range of binding energy from 0 to $1200 \mathrm{eV}$ sub-band under $200 \mathrm{eV}$ of Sodalite solid treated by $0 \mathrm{M}, 0.01 \mathrm{M}$ and $0.1 \mathrm{M} \mathrm{HCl}$ acid. 

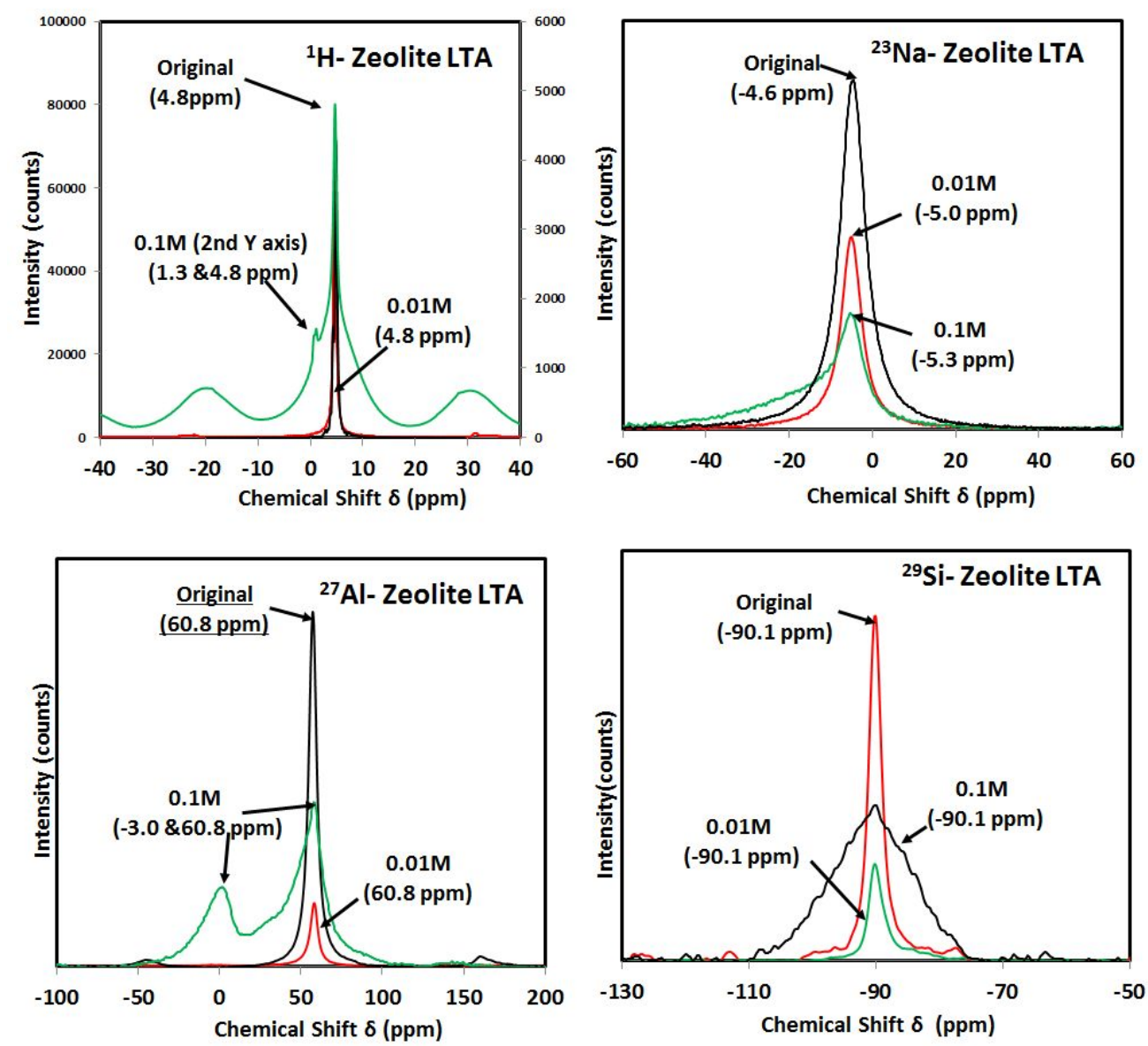

Figure S4. ${ }^{1} \mathrm{H},{ }^{23} \mathrm{Na},{ }^{27} \mathrm{Al}$ and ${ }^{29} \mathrm{Si} \mathrm{NMR}$ spectra of Zeolite LTA phase treated by $0 \mathrm{M}$, $0.01 \mathrm{M}$ and $0.1 \mathrm{M}$ acid. 

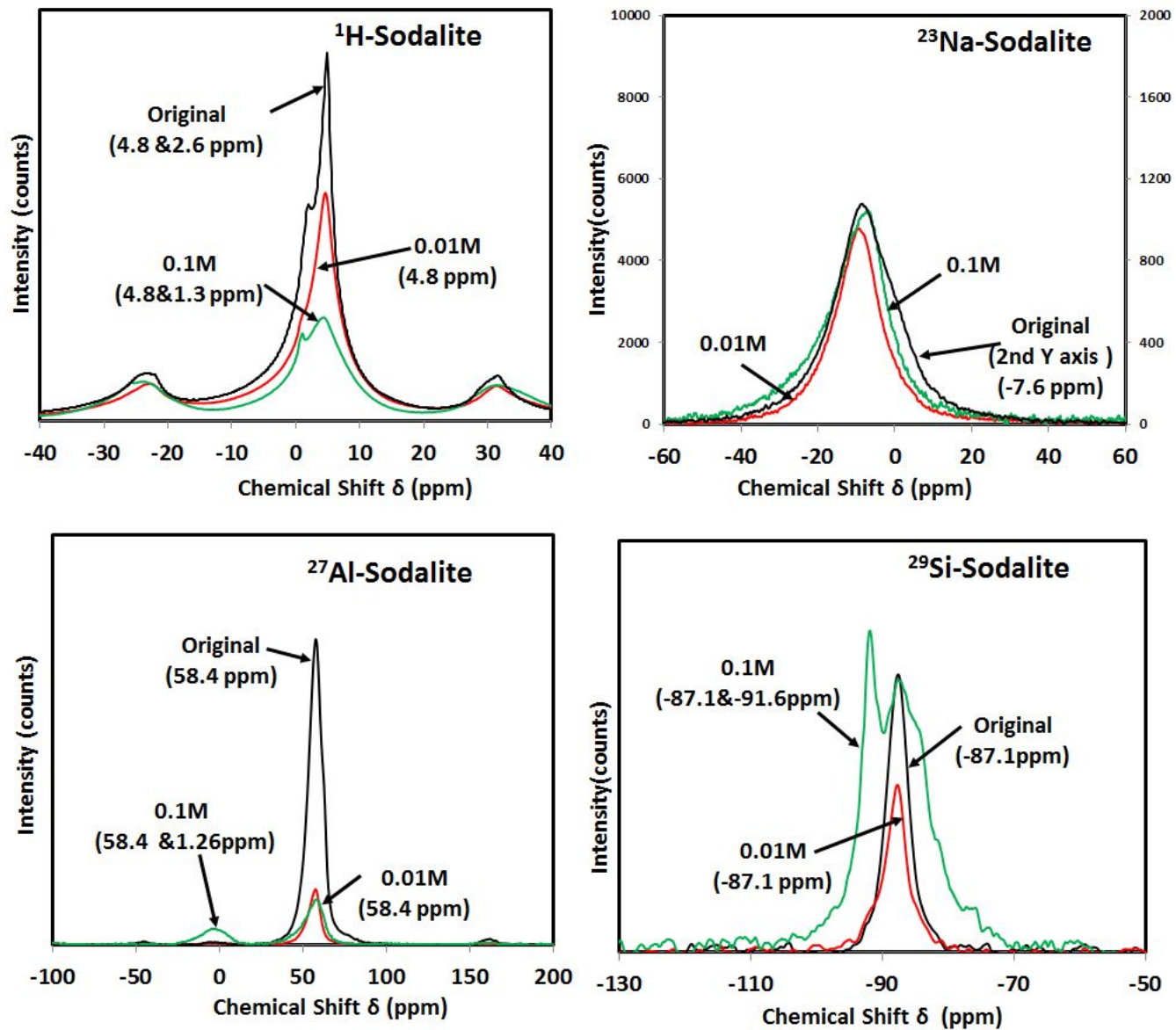

Figure S5. ${ }^{1} \mathrm{H},{ }^{23} \mathrm{Na},{ }^{27} \mathrm{Al}$ and ${ }^{29} \mathrm{Si} \mathrm{NMR}$ spectra of sodalite phase treated by $0 \mathrm{M}$, $0.01 \mathrm{M}$ and $0.1 \mathrm{M}$ acid.

\section{Speciation in aqueous $\mathrm{Al}_{2} \mathrm{O}_{3}-\mathrm{H}_{2} \mathrm{O}$ system}

By use of various measurements, such as Raman, IR and NMR techniques as well as theoretical modelling, many types of aluminate species in acid and caustic aluminate solutions have been reported [1-5]. Monomers, dimers and trimers can all be present together at significant concentration in solution in varying proportion depending on conditions such as temperature and $\mathrm{pH}$. For caustic solution, $\mathrm{Al}(\mathrm{OH})_{4}^{-}$is the predominate specie as solutions in which DSPs are formed, aluminium polymeric species will be insignificant $[3,5]$. However, for neutral and acidic solution, there are various aluminate species existed. Using standard Gibbs energy of formation of species available from literatures or commercial database such as HSC as shown in Table S1, we calculated the equilibrium constant for reactions on equations 1 to 4 [6, 7]. As for the aluminate-water speciation diagram as a function of $\mathrm{pH}$ at the temperature of $25^{\circ} \mathrm{C}$ with total Al species activities of 1 are constructed as shown in Figure S5. It can be shown that the main aluminate species is $\mathrm{Al}^{3+}$ when $\mathrm{pH}$ value is less than 4 with minor fraction of $\mathrm{Al}(\mathrm{OH})^{2+}$. 


$$
\begin{array}{ll}
\mathrm{Al}^{3+}+\mathrm{OH}=\mathrm{Al}(\mathrm{OH})^{2+} & (\text { Equation 1) } \\
\mathrm{Al}(\mathrm{OH})^{2+}+\mathrm{OH}^{-}=\mathrm{Al}(\mathrm{OH})_{2}{ }^{+} & (\text {Equation 2) } \\
\mathrm{Al}(\mathrm{OH})_{2}{ }^{+}+\mathrm{OH}^{-}=\mathrm{Al}(\mathrm{OH})_{3} & (\text { Equation 3) } \\
\mathrm{Al}(\mathrm{OH})_{3}+\mathrm{OH}^{-}=\mathrm{Al}(\mathrm{OH})_{4}{ }^{+} & (\text {Equation 4) }
\end{array}
$$

Table S1 The standard Gibbs energies of formation of species relevant with aluminum ions in $\mathrm{pH}$ value range from 2 to 14 [7] .

\begin{tabular}{|l|c|}
\hline Formula & $\boldsymbol{\Delta G}^{\mathbf{0}}(\mathbf{K J} / \mathbf{m o l})$ \\
\hline $\mathrm{Al}^{3+}$ & -492 \\
\hline $\mathrm{Al}(\mathrm{OH})^{2+}$ & -696 \\
\hline $\mathrm{Al}(\mathrm{OH})^{2+}$ & -900 \\
\hline $\mathrm{Al}(\mathrm{OH})_{3}$ & -1102 \\
\hline $\mathrm{Al}(\mathrm{OH})^{4-}$ & -1306 \\
\hline $\mathrm{OH}^{-}$ & -157 \\
\hline $\mathrm{H}^{+}$ & 0 \\
\hline
\end{tabular}

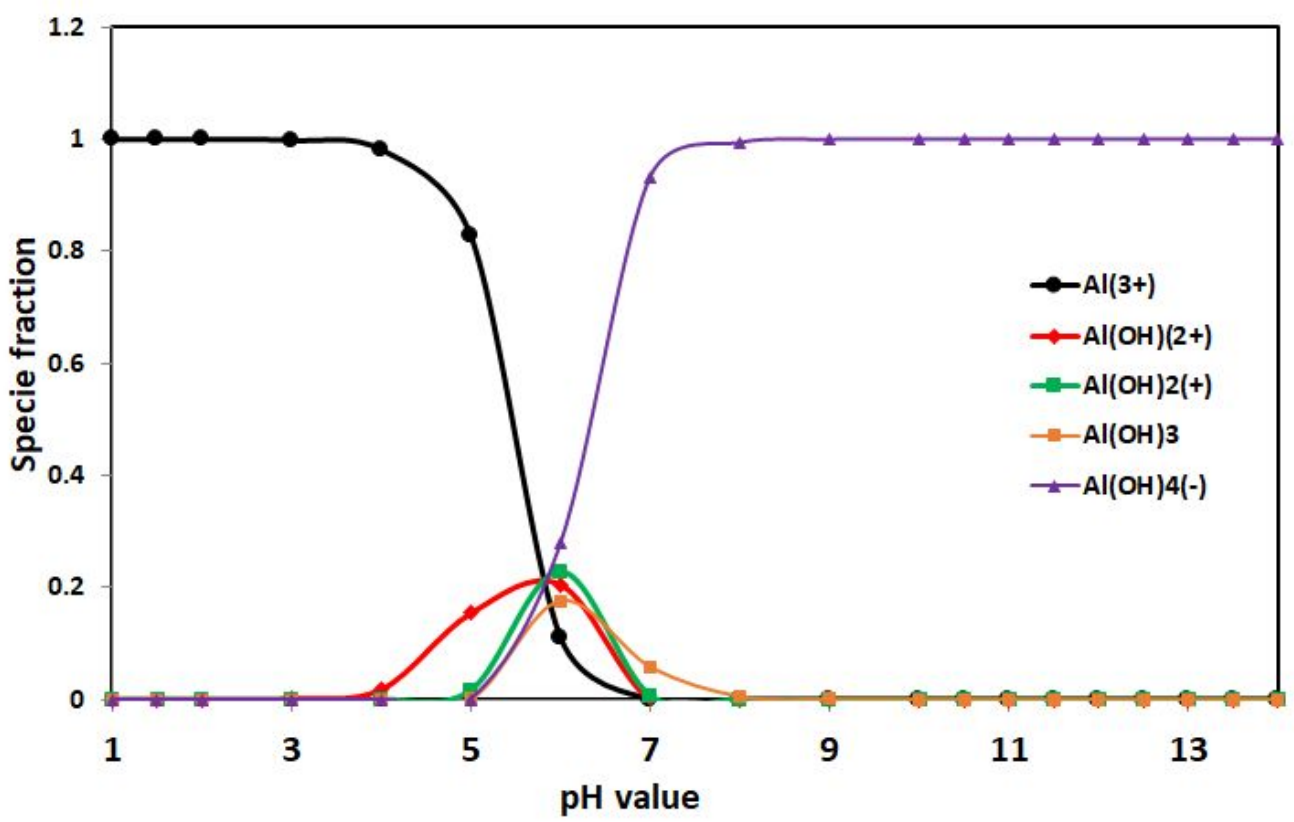

Figure S6. Speciation diagram for the aluminate-water system at $25^{\circ} \mathrm{C}$ as a function of $\mathrm{pH}$ values from 1 to 14 . 


\section{Reference List}

1. Sipos, P., The structure of Al (III) in strongly alkaline aluminate solutions - $A$ review. Journal of Molecular Liquids, 2009. 146(1): p. 1-14.

2. Watling, H., Spectroscopy of concentrated sodium aluminate solutions. Applied Spectroscopy, 1998. 52(2): p. 250-258.

3. Swaddle, T.W., J. Salerno, and P.A. Tregloan, Aqueous aluminates, silicates, and aluminosilicates. Chemical Society Reviews, 1994. 23(5): p. 319-325.

4. Raizman, V., Determination of the Thermodynamic Characteristics of Aluminate Ions. Tsvetn. Met., 1985(5): p. 60-62.

5. Moolenaar, R.J., J.C. Evans, and L. McKeever, Structure of the aluminate ion in solutions at high pH. The Journal of Physical Chemistry, 1970. 74(20): p. 3629-3636.

6. Peng, H., J. Vaughan, and M. Zieba, The thermodynamic approach to predicting silicate solubility, in Proceedings of the 10th International Alumina Quality Workshop. 2015: Perth ,Australia.

7. Roine, A., Outokumpu HSC chemistry for windows: chemical reaction and equilibrium software with extensive thermochemical database. Pori, Finland: Outokumpu, 2014. 